\title{
Could Nearby Pokéstops Improve Restaurants' Online Reputation?
}

\author{
Yuan Zhang \\ University of Texas Arlington \\ yuan.zhang@uta.edu
}

\begin{abstract}
PokemonGo, 2016's most popular and profitable mobile game, promoted people's physical activities and impacted local business by bring new-foot-traffic. Many restaurant managers used it as a marketing tool to improve their traffic, reputation and sales. PokemonGo seems to serve as a positive externality to sales performance and reputation of restaurants with Pokestops nearby and seems to bring positive spill-over to these restaurants. However, windfall is not always there. It is necessary to examine the effectiveness of PokemonGo as marketing tool for restaurants through the information platform Yelp. Our objective is to examine how PokemonGo impacts restaurants' reputation on Yelp.com. By focusing on "Pokestop", we conducted difference-in-difference estimation to investigate the change of restaurants' online-reputation before and after the launch of PokemonGo and with and without Pokestop nearby in both long and short term. We found that in short-run, PokemonGo significantly boosted onlinereputation for restaurants with Pokestop nearby by increasing their review volume, checkin, Elite review number and rating. In long-run, the impacts faded out with PokemonGo's fading populairty. Yet surprisingly, rating in long-run are still significantly improved by the game. Additionally, Restaurant's heterogeneity also influences PokemonGos, effectiveness.
\end{abstract}

\section{Introduction}

In summer 2016, there is a Pokemania all over the world. By the end of 2016, mobile game PokemonGo has been downloaded for more than 750 million times ${ }^{1}$, generated 86 percent more revenue than any other mobile game, captured 11 percent of all mobile game sales ${ }^{2}$, and become one of the most popular and profitable mobile games. This free-to-play locationbased Augmented-Reality (AR) mobile game developed a fashion of players getting out and exercising while enjoying Pokemon collection. In the game, a player's self-created avatar will be displayed

\footnotetext{
${ }^{1}$ https://nianticlabs.com/press/2017/anniversary2017/

${ }^{2} \mathrm{https}$ ://intelligence.slice.com/mobile-gaming-2016-pokemon-gocaught-revenue-game/
}

URI: http://hdl.handle.net/10125/50512

ISBN: 978-0-9981331-1-9

(CC BY-NC-ND 4.0)

\author{
Jie Zhang \\ University of Texas Arlington \\ jiezhang@uta.edu
}

on a virtual map based on the player's real geographical location and avatars move in the virtual map as player move in real world. When encountering a Pokemon, a player can use a Pokeball (an in-game item) to capture it (Figure 1 shows a snapshot of an exciting moment of the game --capturing a Pokemon). Pokeballs and other in-game items can be restocked at Poekstops. Pokestops are re-purposed portals form Ingress (Niantic's previous AR game). They are generally places of interests, which are crowdsourced by first-batch Ingress players (Figure 2). Pokestops make players stay for several reasons: consecutive re-stockings at the Pokestop require a minimum amount of wait intervals, and Pokemon spawn rate can be improved at a Pokestop for a short period of time in certain status, such as dropping a lure module. PokemonGo brings the players and physical stores into an ecosystem. Through the PokemonGo platform, players can interact with the stores in close proximity to a pokestop in the AR virtual environment. ***Figure 1 and Figure 2 About Here***

PokemonGo was so popular that it brought windfall to local businesses, especially restaurants. It lures more new visitors for potential business opportunities [5] [6]. Filloon [5] encouraged owners of those restaurants that happen to have Pokestops nearby to take advantage of this simple AR technology as a marketing tool to attract customers and improve performance. In recent survey studies [4] [15], PokemonGo was found to positively impact players' behaviors in mobility and probability in spending money. Colley [4] found almost half of interviewees had purchased drinks and food at a venue because of PokemonGo-related activities. Zack and Tuss [15] also found significant increase of PokemonGo players' spending money in food and beverage while playing the game. For those restaurants that have Pokestops nearby, owners advertised them by displaying rollup banner showing "We have Pokestops here" [5] [7]. However, there are also concerns or failure of using PokemonGo as a marketing tool. Whitney [5] and Zhu [16] reported that some restaurant managers did not experience more sales or more visits after they dropped lures all day. They claimed that players come in but did not get anything to eat or drink. Given the above mixed 
findings and observations, it is unclear whether AR technology or PokemonGo game will effectively improve business performance by turning the increased PokemonGo players from visits into profits.

Thus, we are interested in studying how PokemonGo affected local business, specifically we examine how PokemonGo impacts restaurants' reputation on Yelp. Yelp.com is one of the most influential crowdsourced local business review websites. A restaurant's reviews and ratings on Yelp affect user's searching results and restaurant choice. More importantly, according to [11] [12], a restaurant's reputation on Yelp directly influence it sale performance and revenue. Right after two weeks of PokemonGo's launch, Yelp added a "Pokestop Nearby" searching filter, and Pokemons and Pokestops information were discussed in restaurant reviews on Yelp website. We empirically investigate the change of restaurants' online reputation before and after the launch of PokemonGo and with and without a Pokestop nearby. We seek to answer three research questions:

(1). Can PokemonGo help restaurants boost their online reputation in short run (in terms of higher rating, bigger volume, more Elite reviews and more checkins)?

(2). Can PokemonGo help restaurants improve their online reputation in long run (in terms of higher rating, bigger volume, more Elite reviews and more checkins)?

(3). Does PokemonGo impact the online reputation of heterogeneous restaurants differently?

To answer these questions, we first crawled and merged PokemonGo's geographic data, PokemonGo's app-store data, restaurant information, and individual reviews from Yelp. Then we used a difference in difference (DD) design, considering restaurants with Pokestop nearby as the treatment group, and restaurants not listed by the filter as the control group, to estimate DD coefficients for each reputation metric. Additionally, we also compared the DD effects under both a long and a short term. To further explore how PokemonGo influences restaurants differently, we partitioned our sample into different subsamples by the median review volume, median rating, and the consumption cost levels to contrast the impacts. For robustness check, we also estimated the dynamic DD effects and checked the parallel trend assumption.

The results of current study confirmed our expectations regarding PokemonGo's impacts on restaurants' online reputation. Three months after the entry of PokemonGo, online reputation was significantly improved by 2.5 percent in rating, 27.3 percent in volume, 8.9 percent in checkin, and 25.7 percent in Elite reviews numbers. However, some of these exciting "adrenaline shot" effects faded out in long run. Only rating, in long run was still significantly improved due to the entry of PokemonGo. Partitioned subsample results showed that the PokemonGo affected restaurants of different popularity, rating levels, and price levels differently.

We contribute to both theory and practices in two folds:

1) We provided a direct and quantitative support to the effectiveness of AR technologies as a marketing tool. This is original in the literature. As far as we know, there are no prior studies that have examined the marketing effects of AR technologies.

2) Our study provides comprehensive examinations to the impacts of PokemonGo on online reputation. Recent literature mainly uses review ratings to measure business reputation [11] [12] [8] [14] Previous literature did not provide exact definition regarding how to measure business' online reputation. We used four different metrics (rating, volume, Elite reviews and checkin) to measure online reputation for a more comprehensive view.

To show the dynamic effect, we conducted the study in short and long terms. We also tested the model with different subsamples to demonstrate the varying impacts of PokemonGo on restaurants of different types.

\section{Research design}

We expect positive impacts of PokemonGo on restaurant reputation metrics. We depict our logic and central idea in Figure 3. Pokestops attract more PokemonGo players to nearby locations than any other place. Players need to walk close to restock ingame items. Each time when a player approaches a Pokestop, restocking items are random and limited. Once Pokestop is hit by a player, this player cannot re-approach the same stop to restock items until fiveminute cool-down finished and the Pokestop is ready again. Thus, players usually stay or walk around Pokestop locations to get more game supplies. When a Pokestop is activated by a "lure" by players, Pokemon spawn rate near this Pokestop will be improved and more players will be attracted to this location and stay longer. When players stroll round Pokestop, they would discover nearby area and may look for food and drink during or after playing ([4] [16]). Therefore, players attracted by Pokestops will be new-foot visitors and potential customers to nearby restaurants. Then if they like or dislike the

\footnotetext{
${ }^{3}$ Given the page limit, literature review section is taken out in this submission, but is ready upon request.
} 
food or drink they tried or if they want to share their Pokémons-food double hunting experience, they could share their voices on Yelp via reviews, or check-ins. Lured customers could also happen to be socially active foodies like Elite yelpers.

Consequently, with more new-foot visits to restaurants nearby Pokestops, these restaurants' review volume, checkin records and Elite review numbers are expected to improve. Pokestop-nearby, as an attractive feature for restaurants, may enlarge restaurants' differentiation, promote consumers' social learning on Yelp, and then improve restaurants overall online reputation.

$$
\text { ***Figure 3. Central idea sketch*** }
$$

\subsection{Identification strategy- Difference in Difference}

Our main objective is to investigate the impact of exposure to Pokéstops on restaurant's online reputation. The primary econometric approach we adopted is difference-in-difference (DD) model for ruling out general market level change. Specifically, we compared changes in Pokéstops-nearby restaurants' reputation metrics before and after the launch of PokémonGo with those of restaurants without Pokéstops nearby over the same time period. To meet the key identification assumption of DD analysis, we need to assume in the counterfactual condition that if there were no PokemonGo entry or Pokestops, restaurants in the treatment group and in the control group would have identical time trends in the changes of reputation metrics.

Based on [1] and [7], the general DD model includes entity fixed effect dummy, time fixed effect dummy and interaction of treatment dummy with time dummy. That general form would be convenient if treatment entry time is different for different entities. Under our research setting, the entry time of PokemonGo is the same for all restaurants. Therefore, we used the basic DD regression model including time dummy, treatment dummy, DD interaction and other control variables. By [1], basic and general form of DD models would provide identical results.

Our main DD estimation equation is:

$O R_{i, s, t}=\gamma P K G_{i}+\lambda d_{t}+\beta\left(P K G_{i}{ }^{*} d_{t}\right)+\delta X_{i, s, t}+$ $\theta_{l} R i+\varepsilon_{i, s, t}$

To describe online reputation through a more comprehensive perspective, we used four reputation metrics as dependent variables and applied DD estimation separately. $O R_{i, s, t}$ is online reputation for restaurant $i$, in state $s$, and at time $t$, which can be $R A_{i, s, t}, V O_{i, s, t}, C H_{i, s, t}$, or $E L_{i, s, t} . V O_{i, s, t}$ is review volume, $\mathrm{CH}_{i, s, t}$ the checkin times, $E L_{i, s, t}$ the Elite review numbers, $R A_{i, s, t}$ the average review rating for restaurant $i$ in state $s$ at time $t$. In equation (1), $P K G_{i}$ is the treatment dummy and $P K G_{s}=1$ when restaurant $i$ listed by Yelp's "Pokestops nearby" filter and 0 otherwise. $d_{t}$ is the time switch. We use month as the time unit. PokémonGo is officially launched on July 62016 . The beta test in US market started at the end of May and ended at the end of June 2016. Thus we chose June 2016 as the entry time. Here, $d_{t}=1$ when the time is after June 2016, and $d_{t}=0$ when $t$ is before. $R_{i}$ is observable restaurant time-invariant fixed effect covariate vector, and $R_{i}=\left(\right.$ Density $_{i}$, Competition , $_{\text {, }}$

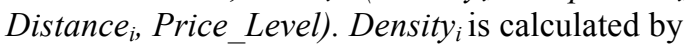
number of Pokestops within a 20-meter radius around restaurant $i$. Competition $_{i}$ is calculated by number of other restaurants within a 20 -meter radius around restaurant $i$. Distance $_{i}$ is the geographical distance between restaurant $i$ and its closest Pokestop. Price_Level is price level vector, including four price level dummies, $\mathrm{P}_{1}, \mathrm{P}_{2}, \mathrm{P}_{3}$, and $\mathrm{P}_{4}$ according to the restaurant's price level $(\$, \$ \$, \$ \$$, or $\$ \$ \$$ ) provided by Yelp. $X_{i, s, t}$ is vector including all other control variables, for example, PokemonGo's popularity and trend variables: PokemonGo's monthly download times and monthly revenue since July 2016. $\varepsilon_{i, s, t}$ is the residual.

To examine online reputation through different perspectives, we conduct DD estimation on four different reputation metrics separately. By applying DD estimation, our main parameters of research interests are the four $\beta s$ the DD coefficients to estimate the average effect of being exposed to Pokestops on the treated restaurants' monthly online reputation variables. Additionally, inspired by [8] and [11], we also expect heterogeneity in the effect of PokemonGo on restaurants' online reputation due to different aggregated review volume and average rating. Meanwhile considering that there may also lies salient difference in the game effect due to long and short time span, we will consider both long term --- January to December 2016, and short term --March to September 2016. We conducted DD estimation on different time spans first. Then we partition the full sample into 8 subsamples by median of annual review volume (AV) and annual average rating $(A R)$ for each restaurant. We run $D D$ estimation one by one for each partitioned sample and summarize and compare the difference in difference coefficients.

\section{Data collection}

We merged four datasets for this study: PokémonGo geographic data, PokémonGo's historical downloads and revenue data from App stores, restaurants business information data crawled from Yelp.com, and daily reviews of these restaurants from Yelp in Dallas and Fort Worth (DFW) area. They are linked through transformed coordinates and business addresses. 


\subsection{PokémonGo data}

The PokémonGo geographic data includes Pokéstops' and Gyms' id numbers and coordinates in Texas. This dataset is collected from Niantic via a third-party API based on a customized python program. The two open source tools we adapted are www.pokémongomap.info, which visualized all PokéStop and gym locations on google map, and pgoapi, which is a third-party PokémonGo developer API provided by pogodev.org. We downloaded and used Pokéstops' and Gyms' coordinates to calculate two control variables, Pokéstop density and distance to nearest Pokéstops for each restaurant. The PokémonGo historical monthly downloads and revenue data was collected manually from Priori data and is merged with Yelp data later as control variables.

\subsection{Restaurant information and reviews}

After the launch of PokémonGo, Yelp provided a searching filter feature called "PokéStop Nearby". After checking this feature, it shows restaurantshunting foodies all restaurants with Pokéstops nearby. All the restaurants in this study are in the DFW area. We first used this filter to download the URLs of restaurants with Pokéstop nearby as the treatment group. We selected the rest restaurants without Pokéstops nearby as the control group. We built crawler simulating manual downloading process to download all business information for restaurants in organic list via crawling first layer information through their URLs. Attributes exacted from business information are restaurants name, address, overall rating, price level, total review volume, and type. Under same mechanism, we built another crawler to download all reviews for through each restaurants URL. Attributes included are: review text, posting date, rating, yelper id, yelper's characteristics, and their Elite level. Since Yelp changes its layout frequently during our data crawling, we dropped several restaurants either going bankrupt during data crawling, having invalid data or no reviews during our data cleaning. We used business address as foreign key to merged business information table and review table. We also used Google Maps API to transfer all restaurants' addresses to coordinates to further calculate geographical control variables via Haversine' formula. There are several missing values in monthly rating for restaurants, we use restaurant's annual average rating (from Jan 2016 to Dec 2016) to replace the missing places.

\subsection{Descriptive statistics}

After data cleaning, there are a total of 59,999 reviews and 1,047,360 observations with 1215 restaurants from January 62016 to December 62016. *** Table 1 About Here ***
Table 1a provides summary statistics of our key variables. The majority restaurants have Pokestops nearby, while 22.47 percent of restaurants do not. ${ }^{4}$ From the static and overall descriptive statistics, we can see that restaurants with Pokestops nearby tend to have higher online review volume but slightly lower average rating than their counterpart in baseline group.

\subsection{Parallel trend assumption preliminary check}

Given that the parallel trend assumption is important to DD estimation's robustness, we did a preliminary check before estimation. Based on [1], the most straightforward and common way to see if parallel trend assumption holds is to plot the control and treatment group trending graph over time and observe the general trend and difference. We calculated and plotted the average reputation metrics of all restaurants with Pokestop-nearby as the treatment group on a monthly basis. Similarly, we averaged the monthly reputation metrics of all the restaurants without Pokestop-nearby as the control group. The trend graphs for four reputation metrics are shown below: review volume (Figure 4.1), rating (Figure 4.2), checkin number (Figure 4.3) and Elite review volume (Figure 4.4). Pre-treatment trend for four metrics between control and treatment groups are generally identical, and differences after the entry of PokemonGo are salient. Therefore, DD estimation can be a proper way for our research design. Formal robustness check will be provided in Section 4.4

$$
\text { *** Figures 4.1 4.2 4.3 4.4 About Here *** }
$$

\section{Findings \\ 4.1 Main results}

The difference in difference estimation results for full model in both long window and short window are reported in the first part of Table 2a. Considering the significant difference in variable scales, we took natural $\log$ for each variable as estimation inputs. *** Table 2a About Here ***

In the first part of Table 2a under sections of Model 1 and Model 2, we estimated the DD coefficient $\beta s$ for full sample in short term (MarchSeptember 2016). DD effects are all significantly positive: $0.273(p<0.01)$ for review volume, 0.089

\footnotetext{
${ }^{4}$ According to Angrist and Pischke's 'Harmless Economics' book and Imbens and Wooldrige's review and discussion regarding recent econometrics developments, unbalanced sample sizes is not one of the threat to DD regression's efficiency and robustness. Meanwhile there are many research, which applied DD as identification strategy, also have unbalanced sample size between treatment group and baseline/control group. For example, in Mayer and Ottaviano (2008) and Liu and Lu (2015), the control groups' sizes are about 25 to 30 percent of the full sample. Therefore, we believe our unbalanced samples can also be representative enough to generate robust analysis result.
} 
$(p<0.01)$ for checkin times, $0.257(p<0.05)$ for Elite review numbers and $0.025(p<0.05)$ for rating. The short-run significant results validate the expectation of PokemonGo's positive impacts on local restaurants and their online reputation. More specifically, these results suggest that being close to a Pokestop consequently improve restaurant's online review volume by 23.7 percent, improve customer's checkin by 8.9 percent, boost Elite review numbers by 25.7 percent and enhance the average rating by 2.5 percent three month after the game launch. To sum up, PokemonGo can be considered as a powerful adrenaline shot for all restaurants for their online image and reputation in short run. Naturally we want to see whether these reputation metrics can still sustainably increase in long run due to PokemonGo. The DD coefficient $\beta s$ for full sample in long window (Jan-Dec 2016) are not so salient such as -0.013 $(p>0.1)$ for monthly volume, $-0.039(p>0.1)$ for monthly checkin, $-0.012(p>0.1)$ for Elite review numbers and $0.066(p>0.01)$ for monthly average rating. Except for the $\beta$ of the average rating metric, other DD effects are all insignificant in the long term.

One possible explanation is that people's intentions to share contents regarding PokemonGo diminish over time. Another explanation could be an 'adrenal side effect'. That is, in the long run, people are getting tired of the game along with its popularity cool-down, and having Pokestop-nearby cannot sustainably grow new-foot traffic for restaurants. Therefore, the game's impact on restaurant's online reputation also faded out. This fading trend is consistent with monthly game downloads and game total revenue (including advertisement and in-app purchase). Full estimation results for full models are provided in Table 3 .

$$
\text { *** Table } 3 \text { About Here *** }
$$

The long-term impact on average rating is still significantly positive. Even though PokemonGo cannot continuously attract more yelper to generate and share voices regarding the restaurants, the game's positive effect on restaurant's rating can help restaurants building up reputation in a positive direction.

\subsection{Partitioned sample results by annual review volume and annual average rating}

Inspired by [9], we also want to find heterogeneous impacts of PokemonGo on different types of restaurants by partitioning the full sample. The subsamples were partitioned by the medians of annual review volume $(\mathrm{AV}=32)$ and annual average rating $(\mathrm{AR}=3.9)$. The $\mathrm{DD}$ estimation results for subsamples including both short and long terms are reported in the second part of Table $2 \mathrm{a}$. From shortterm to long-term there are two salient patterns. First,
Elite yelpers' preference for more popular and less popular restaurants changed from short-term to longterm. Both high AV and low AV restaurants' Elite review numbers are positively improved by PokemonGo if they have Pokestop nearby. However, the long run impact on Elite review volume diverged into two directions. Elite yelpers decreased review generation by 39.8 percent $(p<0.01)$ for less popular restaurants, while they leave more reviews by 9.6 percent $(p<0.05)$ for the more popular restaurants. PokemonGo may attract more Elite yelpers' visits and stimulate their UGC online in the short run. However, in long run, Elite yelpers still prefer more popular restaurants. The second pattern is that if DD effects are all significant, less-popular restaurants' DD coefficients are bigger than more-popular restaurants'. In other words, PokemonGo has a greater impact on less popular restaurants than popular restaurants.

\subsection{Partitioned sample results by restaurant's price level}

Another perspective to check restaurants heterogeneity is to look at them through different price level. While yelper checking in or writing reviews for a restaurant, they also provided their consumption cost range to Yelp. Yelp then calculated the average spending range for each restaurant and classify them into four levels and label them as different number of dollar signs such as ' $\$$ ', ' $\$ \$$ ', ' $\$ \$ \$$ ' and ' $\$ \$ \$ \$$ '. According to the discussions of Yelp online community, price range 5 or the dollar sign can be considered as approximated spending per person. ' $\$$ ' represents spending under $\$ 10$; ' $\$ \$$ ' represents spending from $\$ 11$ to $\$ 30$; ' $\$ \$ \$$ ' represents spending from $\$ 31$ to $\$ 60$; and ' $\$ \$ \$ \$$ ' represents spending above $\$ 61$. To further see heterogeneity in PokemonGo's impact on restaurants' online reputation, we partitioned the full sample based on their price range into four categories. DD estimation coefficients for four reputation metrics are still our main interests and results will be reported also in short and long run in Table $2 \mathrm{~b}$. $* * *$ Table $2 \mathrm{~b}$ About Here $* * *$

Not surprisingly, the overall PokemonGo causal impacts on four metrics are consistent with the main effect full model in both short and long run. There is also a pattern regarding Elite yelpers' preference: Both high-end and budget restaurants' Elite review numbers are positively improved by PokemonGo if they have Pokestop nearby. However, in long run, Elite yelpers still prefer high-end restaurants. For

\footnotetext{
${ }^{5}$ https://www.yelp.com/topic/san-diego-can-anyone-give-me-theactual-dollar-range-for-the-dollar-sign-symbols-in-rrgards-topricing
} 
budget restaurants in long run review volume, checkin and Elite review numbers did not continuously increase after the boost in short-run. Some of the DD coefficients are even insignificantly negative. This sad sluggishness is consistent with the game decreasing popularity trend in APP store for same period. On the other side of the dining market, for high-end restaurants, at least monthly review volume and Elite review volume are significantly improved by being close to Pokestops. There is also a noticeable pattern changing in Elite yelper's preference that in long run, Elite yelpers still prefer high-end restaurants even though PokemonGo attract Elite yelpers' attention to both budget and high-end restaurants in short term. Especially for restaurants in price level 4, review volume is almost tripled in long run, boosting by 292.5 percent $(p<0.05)$ and the Elite review numbers also increased by 130.6 percent $(p<0.05)$.

Based on standard learning model and Luca's work in [11] [12], rating can be considered as a simplified heuristic for consumers learning about restaurants quality. For high-end restaurants, PokemonGo's significant improvement in online popularity will improve customers' social learning on Yelp and will highly probably improve the actual visits. For budget restaurants, even though short-term boost faded, in long term PokemonGo at the same time bring a hope out of box--- better reputation, higher significant positive rating. In short and long run, rating of budget restaurants all increased by 0.2 percent $(p<0.05)$ to 7.2 percent $(p<0.01)$. We believe PokemonGos' improvement in overall restaurants' rating could enhance consumer's learning and perceiving about these restaurants' quality.

\subsection{Robustness check- Dynamic effects}

One of the typical biases under the DD research design setting ([8] [9]) is restaurants' owners' selfselection bias towards whether to become a location with Pokestop nearby. The self-selection could jeopardize the randomness of treatments and will threat to the validity of DD estimation results. Here in our research setting, as we explained in previous section, restaurant owners do not have any right to turn their business locations into a Pokestop.

Pokestops and Gyms databases are constructed based on Niantic's portal database for Ingress, which is another much older augmented reality mobile game similar to PokemonGo. Pokestops in PokemonGo are almost all imported from Portals in Ingress expect for some locations without safe pedestrian access. When Ingress was initially developed, Niantic Labs relied on crowdsourced locations for Ingress Portals ${ }^{6}$. Niantic let first several batch players to select and apply locations as Portals. Locations can be any interesting places except for some probation, such as natural feature landscapes, and private properties etc. but not limited to any types of business areas. Yet according to the Candidate Portal Criteria, since Dec 31,2014 , when it is way too ahead of the development of PokemonGo (October 2015), Nitanic has no longer accepted new requests for more locations for Ingress. That means first, Pokestop locations have been a set of fixed coordinates till now and are not affected by the restaurants' owners' selection and wills. Second, all Pokestops are crowdsourced, which can be considered random and independent with and irrelevant to restaurant owners' wills. Therefore, the randomness of treatments was not affected by restaurant owner's self-selection towards whether to make their business location closer to a Pokestop and accordingly there is no selfselection bias in our research design.

Another crucial issue regarding robustness is the key assumption of DD estimation: the counterfactual treatment group and the control group are supposed to have the same time trends. One of the classic way to examine the violation of the parallel trend assumption ([10] [3]) and validity of DD estimation ([2] [13]) is to: first, include interactions between time fixed effect and treatment dummy for four pretreatment months (January to April) ahead of the game entry month and remove the interaction for last pre-treatment month (May) given dummy variable trap; second, rewrite the following interactions related to the omitted month, May, which is served to be the baseline. Thus, if our four online-reputation metrics satisfy the parallel trend assumption, the preDD coefficients would be insignificant while postDD coefficients would be significant. According to [2] and [13], the distinctive advantage of this method is that interaction terms after treatment applying are shown in a dynamic and informative way, such that we can tell how DD effects fade out. Specifically, the above method is to expand equation (1) into the generalized expression and form the interaction form such that:

$$
\begin{gathered}
\text { ORi, } s, t=\sum_{j=0}^{m} \beta_{i, t-j} * D_{i, t-j}+\sum_{j=1}^{q} \beta_{i, t-j} * \\
D_{i, t+j}+\delta X i, s, t+\theta R i+\varphi_{i}+\emptyset_{t}+e_{i, t}
\end{gathered}
$$

where $D_{i, t-j}$ equals 1 if at $(t-j)$ month, restaurant $i$ is affected by PokemonGo via being close to a Pokestop; else 0. $D_{i, t-j}$ describes the treatment's lag effect. $D_{i, t-j}$ accordingly depicts the treatment's lead effect. Based on [2], if the parallel trend assumption

\footnotetext{
${ }^{6} \mathrm{http}: / /$ www thisisinsider.com/why-are-pokemon-go-locationsrandom-2016-7
} 
holds, all 'leads' should be insignificant or all $\beta_{j}$ insignificant, meanwhile all or partial 'lags' should be significant or all or partial $\beta-j$ insignificant. The dynamic effect results for each variable are summarized at Table 4.

*** Table 4 and Figure 5 About Here ***

From Table 4, all 'lead' coefficients are insignificant and most of 'lag' coefficients are significant. The parallel trend assumption holds under our research setting, and our DD estimation model are strongly robust. Additionally, trends for volume, checkin, Elite volume and rating are consistent with previous estimation models for both long and short run. DD effects due to PokemonGo can be considered salient from.

\section{Conclusion, implication and future work}

PokemonGo did form the players and physical stores an ecosystem. Through the PokemonGo platform, interaction between stores with Pokestops nearby and customers improved both stores' performance and customers' satisfaction. Our paper provided a timely and comprehensive empirical analysis of PokemonGo's effectiveness as a marketing tool and its impacts on local restaurants' online reputation. For short run, being close to PokemonGo could significantly boost local business online reputation metrics including rating, review volume, valence, checkin records and Elite review numbers, however, most metrics did not have sustainable growth in long-run. Rating, is still shown as significantly improved in long-run, suggesting that the entry of PokemonGo generally improved customers' perceived quality and impression of restaurants with Pokestops nearby. Additionally, restaurant's heterogeneity also influences PokemonGo's effectiveness. We compared the reputation metrics of different types of restaurants in both long and short run and found some implications for restaurant owners. (1) PokemonGo has a greater impact on less popular restaurants than popular restaurants. For less-popular restaurants, owners could take advantage of PokemonGo and launch promotion related to game theme to boost visits and reputation in short run. (2) Elite yelpers' preference for more popular and less popular restaurants changed from short-term to long-term. For more popular restaurants in long-run, continuously providing offers related to PokemonGo theme or exclusively for Elite yelpers could help the restaurants further form a sustainable improvement in their online reputation. (3) In long run, Elite yelpers still prefer high-end restaurants. High-end restaurants' managers could also use PokemonGo-themed Elite yelper exclusively offer to maintain a stable increase in Elite Yelper's preference.

PokemonGo as the most successful LBS-AR mobile application, indeed provided positive externality to local businesses. Windfall the game brought can be further explored if there are public sales or reservation data from Yelp. However, based on large-scale observations and previous research studies, we believe, the exciting improvement in online reputation thanks to PokemonGo can also bring better sales performance and revenue to restaurants with Pokestops nearby. For future work in the next phase, we will first conduct a topic modeling analysis via LDA to examine PokemonGo related topics' heat and trend in Yelp reviews in order to investigate how PokemonGo influences Yelper's intention of writing reviews. Second, a Coarsened Exact Matching model will be provided as an alternative to our DD estimation model.

For future studies, there are two places that could be improved. First, since we don't have restaurant's sales or real traffic data, we couldn't empirically measure how much PokemonGo improved restaurant's performance such as in new-foot visits or sales revenue. If sales or real visit data are available, PokemonGo's direct impact could be shown more saliently and convincingly. Second, till summer 2017, Nitantic has been updated the game and lanched PokemonGo's third generation. The saying "PokemonGo is dying" is no longer the truth. Future study can continuously scrape game updates and Yelp reviews to see how this LBS-AR fun technology impact local business in longer time.

\section{Reference}

[1] Angrist, Joshua D., and Jörn-Steffen Pischke. Mostly Harmless Econometrics: An Empiricist's Companion. Princeton University Press, 2008.

[2] Autor, David H. "Outsourcing at Will: The Contribution of Unjust Dismissal Doctrine to the Growth of Employment Outsourcing." Journal of Labor Economics 21.1 (2003): 142.

[3] Che, Yi, et al. "Once an Enemy, Forever an Enemy? The Long-run Impact of the Japanese Invasion of China from 1937 to 1945 on Trade and Investment." Journal of International Economics 96.1 (2015): 182-198.

[4] Colley, Ashley, et al. "The Geography of PokémonGO: Beneficial and Problematic Effects on Places and Movement." Proceedings of the 2017 CHI Conference on Human Factors in Computing Systems. ACM 2017.

[5] Filloon, Whitney "How Restaurants Are Dealing with Pokémon Go Mania”, Eater. Jul 11, 2016.

[6] Fulton, Wil "'Pokemon Go' Is Going to Make Restaurants and Bars Tons of Money”, Thrillist. Jul 12, 2016.

[7] Imbens, Guido W., and Jeffrey M. Wooldridge. "Recent Developments in the Econometrics of Program 
Evaluation." Journal of Economic Literature 47.1 (2009): 5-86.

[8] Li, X. "Could Deal Promotion Improve Merchants' Online Reputations? The Moderating Role of Prior Reviews." Journal of Management Information Systems 33.1 (2016): 171-201.

[9] Li, X. "Impact of Average Rating on Social Media Endorsement: The Moderating Role of Rating Dispersion and Discount Threshold." Forthcoming at Information Systems Research (2017).

[10] Lu, Y., Tao, Z. and Zhu, L. "Identifying FDI spillovers." Journal of International Economics 107 (2017): 75-90.

[11] Luca, M. "Reviews, reputation, and revenue: The case of Yelp. com." Working paper, Harvard Business School (2016).
[12] Luca, M., and G. Zervas. "Fake it till you make it: Reputation, competition, and Yelp review fraud." Management Science 62.12 (2016): 3412-3427.

[13] Pischke, Jörn-Steffen. "Labor market institutions, wages, and investment: Review and implications." CESifo Economic Studies 51.1 (2005): 47-75.

[14] Wang, L., Gopal, R., Shankar, R. and Pancras, J. "On the Brink: Predicting Business Failure with Mobile Location-Based Checkins." Decision Support Systems 76 (2015): 3-13.

[15] Zach, Florian J., and Iis P. Tussyadiah. "To Catch Them All-The (Un) intended Consequences of Pokémon GO on Mobility, Consumption, and Wellbeing."

Information and Communication Technologies in Tourism 2017. Springer, Cham, 2017. 217-227.

[16] Zhu, Y. "5 Brilliant Ways Restaurants Are Using Pokémon Go to Level up Sales". Forbes. Jul 16, 2016.
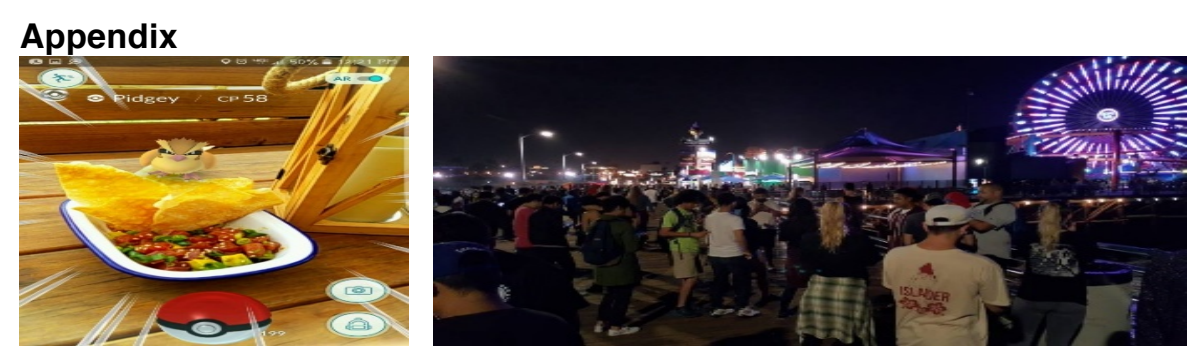

Figure 1(Left). PokemonGo Spawn Screen

Figure 2(Right). Hundreds of PokemonGo Players Gather at the Santa Monica Pier Pokestop

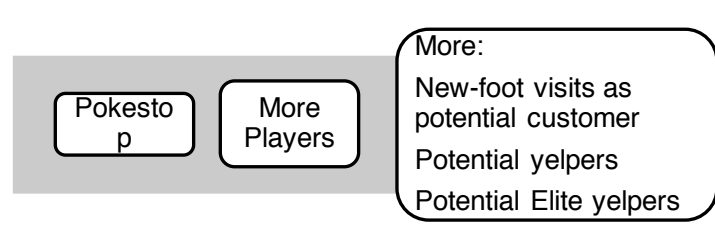
Betterondine-reputation
Rating
Review volume
Checkin
Elite reviews

Figure 3. Central idea

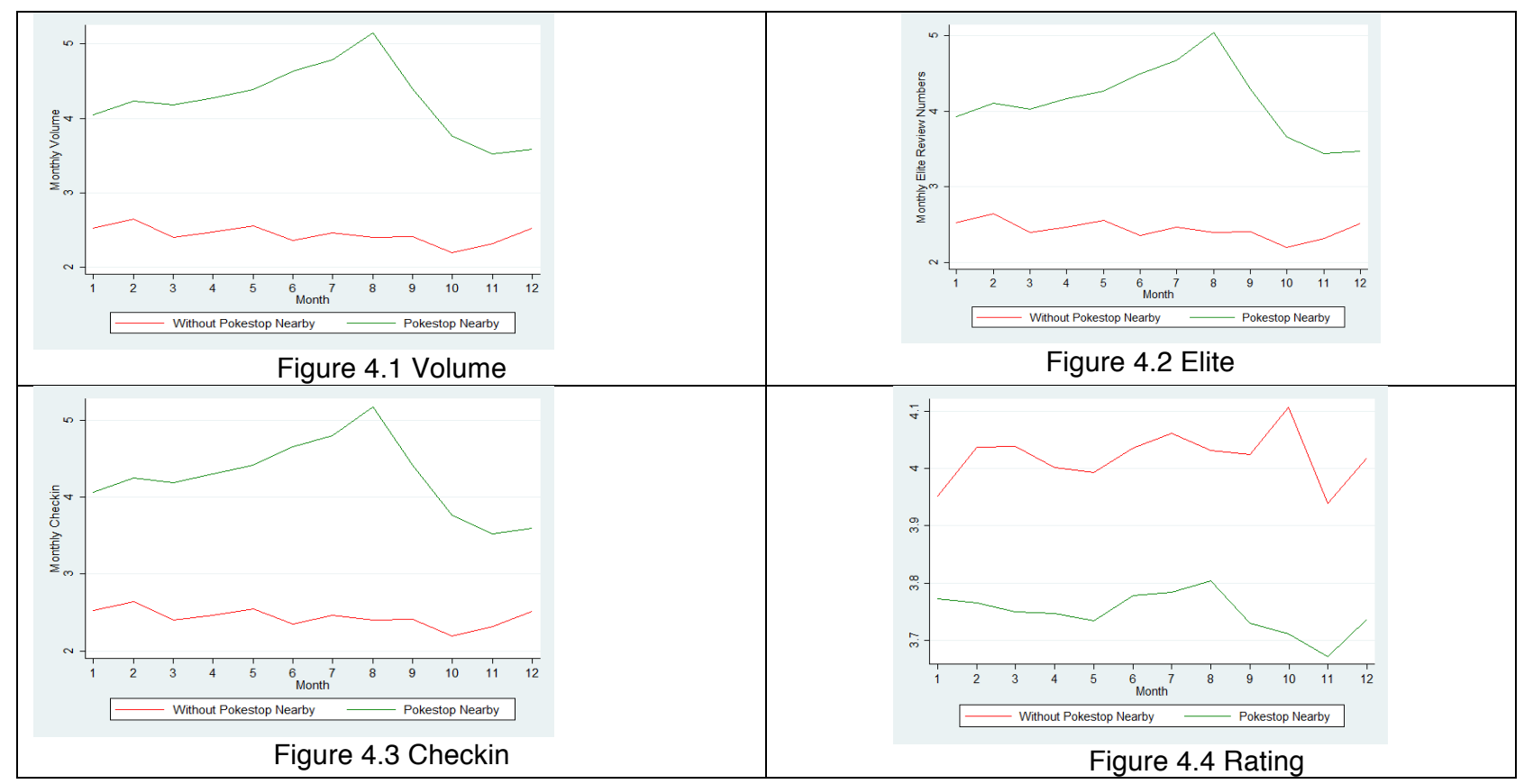


Table 3. Estimation Results for Full Model

\begin{tabular}{|c|c|c|}
\hline \multicolumn{3}{|c|}{ DV $=$ Review Volume } \\
\hline Variables & 1-12 Month & 3-9 Month \\
\hline $\begin{array}{l}\text { DD effects } \\
\text { Ln }\end{array}$ & $-0.013(0.024)$ & $0.273^{\star \star}(0.135)$ \\
\hline Competition & $0.022^{\star \star \star}(0.005)$ & $0.001^{\star \star \star}(0.001)$ \\
\hline Ln Density & $-0.013^{\star}(0.007)$ & $0.000(0.001)$ \\
\hline $\begin{array}{l}\text { Ln Distance } \\
\text { Ln Game }\end{array}$ & $-0.012(0.009)$ & $0.000(0.001)$ \\
\hline Downloads & $0.018(0.014)$ & $0.001(0.001)$ \\
\hline $\begin{array}{l}\text { Ln Game } \\
\text { Revenue }\end{array}$ & $0.034^{\star \star \star}(0.012)$ & $0.002^{\star \star \star}(0.001)$ \\
\hline \multicolumn{3}{|c|}{$\mathrm{DV}=$ Checkin } \\
\hline Variables & 1-12 Month & 3-9 Month \\
\hline $\begin{array}{l}\text { DD effects } \\
\text { Ln }\end{array}$ & $-0.039(0.025)$ & $0.089^{\star \star \star}(0.03)$ \\
\hline Competition & $0.001^{* \star \star}(0.001)$ & $0.001(0.001)$ \\
\hline Ln Density & $0.000(0.000)$ & $0.000(0.001)$ \\
\hline $\begin{array}{l}\text { Ln Distance } \\
\text { Ln Game } \\
\text { Downloads }\end{array}$ & $0.001(0.003)$ & $0.000(0.001)$ \\
\hline $\begin{array}{l}\text { Ln Game } \\
\text { Revenue }\end{array}$ & $0.001^{* \star \star}(0.001)$ & $0.001^{\star \star \star}(0.001)$ \\
\hline \multicolumn{3}{|c|}{ DV $=$ Elite Review Numbers } \\
\hline Variables & 1-12 Month & 3-9 Month \\
\hline DD effects & $-0.012(0.024)$ & $0.257^{\star \star}(0.125)$ \\
\hline $\begin{array}{l}\text { Ln } \\
\text { Competition }\end{array}$ & $0.003^{\star \star \star}(0.000)$ & $0.002^{\star \star \star}(0.001)$ \\
\hline Ln Density & $-0.002^{*}(0.001)$ & $-0.001(0.001)$ \\
\hline Ln Distance & $0.000(0.001)$ & $0.002(0.001)$ \\
\hline $\begin{array}{l}\text { Ln Game } \\
\text { Downloads }\end{array}$ & $0.000(0.001)$ & $0.001(0.001)$ \\
\hline $\begin{array}{l}\text { Ln Game } \\
\text { Revenue }\end{array}$ & $0.004^{\star \star \star}(0.001)$ & $0.001^{* * \star}(0.001)$ \\
\hline \multicolumn{3}{|c|}{$\mathrm{DV}=$ Rating } \\
\hline Variables & 1-12 Month & 3-9 Month \\
\hline $\begin{array}{l}\text { DD effects } \\
\text { Ln }\end{array}$ & $0.066^{\star \star *}(0.013)$ & $0.025^{\star *}(0.01)$ \\
\hline Competition & $0.000(0.001)$ & $0.001(0.001)$ \\
\hline Ln Density & $-0.001(0.001)$ & $0.000(0.001)$ \\
\hline $\begin{array}{l}\text { Ln Distance } \\
\text { Ln Game }\end{array}$ & $0.001(0.0002)$ & $0.000(0.001)$ \\
\hline Downloads & $0.002(0.001)$ & $0.001(0.001)$ \\
\hline $\begin{array}{l}\text { Ln Game } \\
\text { Revenue }\end{array}$ & $0.001^{\star \star \star}(0.001)$ & $0.001^{\star \star \star}(0.001)$ \\
\hline
\end{tabular}

Table 1. Summary of Data Description

\begin{tabular}{|c|c|c|c|c|}
\hline \multirow[b]{3}{*}{ Variables } & \multicolumn{4}{|c|}{ Summary Statistics, 1-12 Month } \\
\hline & (1) & (2) & (3) & $(2)-(3)$ \\
\hline & $\begin{array}{c}\text { Full } \\
\text { Sample }\end{array}$ & $\begin{array}{c}\text { Pokestop } \\
\text { Nearby }\end{array}$ & $\begin{array}{c}\text { No } \\
\text { Pokest } \\
\text { op } \\
\text { Nearby }\end{array}$ & \\
\hline $\begin{array}{l}\text { Review } \\
\text { Volume }\end{array}$ & $\begin{array}{c}3.839 \\
(5.3725)\end{array}$ & $\begin{array}{c}4.245 \\
(5.788)\end{array}$ & $\begin{array}{c}2.438 \\
(3.213)\end{array}$ & $1.807^{\star \star \star}$ \\
\hline $\begin{array}{l}\text { Checkin } \\
\text { Elite }\end{array}$ & $\begin{array}{c}3.852 \\
(5.389)\end{array}$ & $\begin{array}{c}4.262 \\
(5.806)\end{array}$ & $\begin{array}{c}2.438 \\
(3.213)\end{array}$ & $1.824^{\star \star \star}$ \\
\hline $\begin{array}{l}\text { Review } \\
\text { Volume }\end{array}$ & $\begin{array}{c}3.750 \\
(4.988)\end{array}$ & $\begin{array}{c}4.130 \\
(5.334)\end{array}$ & $\begin{array}{c}2.438 \\
(3.213)\end{array}$ & $1.692^{\star \star \star}$ \\
\hline Rating & $\begin{array}{r}3.810 \\
(4.988) \\
\end{array}$ & $\begin{array}{r}3.749 \\
(0.943) \\
\end{array}$ & $\begin{array}{c}4.019 \\
(0.914) \\
\end{array}$ & $-0.271^{\star \star *}$ \\
\hline \multicolumn{5}{|c|}{ b. Summary Statistics, 4-9 Month } \\
\hline & $(1)$ & $(2)$ & $(3)$ & $(2)-(3)$ \\
\hline Variables & $\begin{array}{c}\text { Full } \\
\text { Sample }\end{array}$ & $\begin{array}{c}\text { Pokestop } \\
\text { Nearby }\end{array}$ & $\begin{array}{c}\text { No } \\
\text { Pokest } \\
\text { op } \\
\text { Nearby }\end{array}$ & \\
\hline $\begin{array}{l}\text { Review } \\
\text { Volume }\end{array}$ & $\begin{array}{c}4.119 \\
(5.859)\end{array}$ & $\begin{array}{c}4.605 \\
(6.357)\end{array}$ & $\begin{array}{c}2.441 \\
(3.118)\end{array}$ & $2.163^{\star \star \star}$ \\
\hline Checkin & $\begin{array}{c}4.136 \\
(5.884)\end{array}$ & $\begin{array}{c}4.628 \\
(6.385)\end{array}$ & $\begin{array}{c}2.442 \\
(3.118)\end{array}$ & $2.186^{\star \star \star}$ \\
\hline $\begin{array}{l}\text { Elite } \\
\text { Review } \\
\text { Volume }\end{array}$ & $\begin{array}{c}4.029 \\
(5.486)\end{array}$ & $\begin{array}{c}4.489 \\
(5.922)\end{array}$ & $\begin{array}{c}2.441 \\
(3.117)\end{array}$ & $2.047^{\star * *}$ \\
\hline Rating & $\begin{array}{c}3.821 \\
(0.938)\end{array}$ & $\begin{array}{c}3.763 \\
(0.937)\end{array}$ & $\begin{array}{c}4.024 \\
(0.914)\end{array}$ & $-.2613^{\star \star \star}$ \\
\hline
\end{tabular}

For Table1, Table 3 and Table 2a, 2b, 4,

Standard errors in parentheses. ${ }^{\star} p<0.1,{ }^{* *} p<0.05,{ }^{\star \star *} p<0.01$

\begin{tabular}{l|c|c}
\hline \multicolumn{2}{|c}{ Table 2a. Main results (AV, AR subsamples) } \\
\cline { 2 - 3 } & $1-12$ Month & 3-9 Month \\
\hline DV= Review & Model 1 & Model 2 \\
Volume & $-0.013(0.024), 0.52$ & $0.273^{\star \star}(0.135), 0.82$ \\
DV= Checkin & $-0.039(0.025), 0.5$ & $0.089^{* \star *}(0.03), 0.57$ \\
DV= Elite Review & $-0.012(0.024), 0.53$ & $0.257^{\star \star}(0.125), 0.82$ \\
Volume &
\end{tabular}




\begin{tabular}{|c|c|c|c|c|}
\hline \multirow[t]{3}{*}{$\mathrm{DV}=$ Rating } & \multicolumn{2}{|c|}{$0.066^{\star * \star}(0.013), 0.88$} & \multicolumn{2}{|c|}{$0.025^{\star \star}(0.01), 0.96$} \\
\hline & $A V>=32$ & $\mathrm{AV}<32$ & $A V>=32$ & $A V<32$ \\
\hline & Model 3 & Model 4 & Model 7 & Model 8 \\
\hline $\mathrm{DV}=$ Review & & & & $0.242^{\star \star}(0.101)$ \\
\hline Volume & $0.012^{\star \star}(0.005), 0.56$ & $0.013(0.029), 0.21$ & $0.327(0.265) 0.82$ & 0.16 \\
\hline $\mathrm{DV}=$ Checkin & $-0.036(0.041), 0.5$ & $-0.011^{\star}(0.006), 0.78$ & $0.112^{\star \star}(0.05), 0.57$ & $\begin{array}{c}0.345^{\star \star}(0.162) \\
0.81\end{array}$ \\
\hline $\begin{array}{l}\text { DV = Elite Review } \\
\text { Volume }\end{array}$ & $0.096^{\star \star}(0.039), 0.52$ & $-0.398^{\star \star \star}(0.103), 0.79$ & $0.025^{\star \star \star}(0.009), 0.83$ & $\begin{array}{c}0.452^{\star \star}(0.186) \\
0.65\end{array}$ \\
\hline \multirow[t]{3}{*}{ DV = Rating } & $0.049^{\star \star}(0.021), 0.89$ & $0.069^{\star \star \star}(0.018), 0.88$ & $0.003^{\star \star \star}(0.001), 0.9$ & $0.030^{\star \star}(0.014), 0.9$ \\
\hline & $\mathrm{AR}>=3.9$ & $\mathrm{AR}<3.9$ & $A R>=3.9$ & $\mathrm{AR}<3.9$ \\
\hline & Model 5 & Model 6 & Model 9 & Model 10 \\
\hline $\mathrm{DV}=$ Review & & & & \\
\hline Volume & $-0.024(0.03), 0.56$ & $-0.104(0.179), 0.76$ & $0.338^{\star \star}(0.166), 0.84$ & $\begin{array}{c}0.158(0.229), 0.79 \\
0.142^{\star \star \star}(0.051)\end{array}$ \\
\hline DV = Checkin & $-0.009(0.006), 0.76$ & $-0.016(0.042), 0.49$ & $0.254(0.167), 0.82$ & 0.57 \\
\hline $\begin{array}{l}\text { DV = Elite Review } \\
\text { Volume }\end{array}$ & $-0.011^{\star}(0.006), 0.83$ & $0.028(0.04), 0.47$ & $0.373^{\star \star}(0.160), 0.85$ & $0.067(0.198), 0.78$ \\
\hline $\mathrm{DV}=$ Rating & $0.017(0.013), 0.85$ & $0(0.001), 0.88$ & $0.002(0.008), 0.85$ & $0.012(0.019), 0.9$ \\
\hline
\end{tabular}

Table 2b. Main results (Price level subsamples)

\begin{tabular}{|c|c|c|c|c|}
\hline & \multicolumn{2}{|c|}{ 1-12 Month } & \multicolumn{2}{|c|}{ 3-9 Month } \\
\hline & Price Level=1, P1 & Price Level=2, P2 & Price Level=1, P1 & Price Level=2, P2 \\
\hline & Model 11 & Model 12 & Model 15 & Model 16 \\
\hline DV $=$ Review Volume & $-0.017^{\star \star}(0.008), 0.84$ & $0.006(0.034), 0.5$ & $0.329^{\star}(0.196), 0.88$ & $0.071^{\star}(0.042), 0.56$ \\
\hline $\mathrm{DV}=$ Checkin & $-0.017(0.040), 0.5$ & $-0.409^{* * \star}(0.151), 0.78$ & $0.080 *(0.048), 0.57$ & $0.074^{\star}(0.043), 0.57$ \\
\hline $\begin{array}{l}\text { DV = Elite Review } \\
\text { Volume }\end{array}$ & $0.020(0.039), 0.52$ & $-0.015^{\star \star}(0.006), 0.9$ & $0.345^{\star}(0.18), 0.81$ & $0.232(0.178), 0.83$ \\
\hline \multirow[t]{3}{*}{$\mathrm{DV}=$ Rating } & $0.060^{\star * \star}(0.022), 0.89$ & $0.072^{\star \star \star}(0.018), 0.88$ & $0.002^{* *}(0.001), 0.9$ & $0.025^{\star}(0.014), 0.9$ \\
\hline & Price Level=3, P3 & Price Level=4, P4 & Price Level=3, P3 & Price Level=4, P4 \\
\hline & Model 13 & Model 14 & Model 17 & Model 18 \\
\hline $\mathrm{DV}=$ Review Volume & $0.227(0.213), 0.9$ & $2.925^{\star \star}(1.338), 0.8$ & $0.174(0.271), 0.9$ & $2.075(1.597), 0.9$ \\
\hline DV = Checkin & $0.027(0.114), 0.49$ & $-0.895(1.107), 0.9$ & $0.308^{\star *}(0.139), 0.6$ & $-0.132(0.076), 0.9$ \\
\hline $\begin{array}{l}\text { DV= Elite Review } \\
\text { Volume }\end{array}$ & $0.041^{\star \star \star}(0.015), 0.9$ & $1.306^{\star \star}(0.621), 0.9$ & $0.052^{\star \star *}(0.017), 0.9$ & $1.490(1.496), 0.9$ \\
\hline $\mathrm{DV}=$ Rating & $0(0.002), 0.9$ & $0.001(0.002), 0.9$ & $0.004(0.002), 0.9$ & $0.001^{\star}(0.001), 0.9$ \\
\hline
\end{tabular}

Table 4. Robustness check, dynamic effects of DID

\begin{tabular}{|c|c|c|c|c|c|c|c|c|}
\hline & \multicolumn{2}{|c|}{ Review Volume } & \multicolumn{2}{|c|}{ Checkin } & \multicolumn{2}{|c|}{ Elite Reviews } & \multicolumn{2}{|c|}{ Rating } \\
\hline & Coef(Std.Err.) & $p$ & Coef(Std.Err.) & $p$ & Coef(Std.Err.) & $p$ & Coef(Std.Err.) & $p$ \\
\hline 2 Month Prior & $0.108(0.171)$ & 0.528 & $0.258(0.230)$ & 0.263 & $0.07(0.207)$ & 0.734 & $-0.029(0.008)$ & 0.251 \\
\hline 1 Month Prior & $0.322(0.178)$ & 0.071 & $0.558(0.253)$ & 0.072 & $0.176(0.203)$ & 0.387 & $-0.061(0.008)$ & 0.305 \\
\hline Current & $0.498(0.202)$ & 0.014 & $0.759(0.268)$ & 0.005 & $0.595(0.261)$ & 0.023 & $0.024(0.009)$ & 0.006 \\
\hline 1 Month Post & $0.611(0.225)$ & 0.007 & $0.822(0.264)$ & 0.002 & $0.626(0.252)$ & 0.013 & $0.017(0.008)$ & 0.037 \\
\hline 2 Month Post & $1.021(0.223)$ & 0.000 & $1.314(0.266)$ & 0.000 & $1.003(0.252)$ & 0.000 & $0.050(0.007)$ & 0.000 \\
\hline 3 Month Post & $0.625(0.224)$ & 0.005 & $0.692(0.226)$ & 0.002 & $0.356(0.187)$ & 0.047 & $0.075(0.007)$ & 0.000 \\
\hline 4 Month Post & $0.279(0.200)$ & 0.017 & $0.328(0.201)$ & 0.103 & $0.04(0.163)$ & 0.800 & $0.077(0.006)$ & 0.000 \\
\hline
\end{tabular}

